Table 1. Summary of ANN scores. A) Global Still's disease evaluation. B) Immune system component. ANN scores mean the probability of the resulted relationship is true positive: +++ correspond to values $>78 \%$ ( $p$-value $<0.05) ;++$ correspond to values $>59 \%(p$-values $<0.15)$ and; + correspond to values $>38 \%(p-$ value $<0.25)$

\begin{tabular}{|c|c|c|c|c|c|c|}
\hline \multirow[t]{2}{*}{ A) Still's disease molecular definition } & \multicolumn{4}{|c|}{ Biologics } & \multicolumn{2}{|c|}{ Non-biologics } \\
\hline & Anakinra & Canakinumab & Sarilumab & Tocilizumab & Methotrexate & Prednisone \\
\hline Still's disease & $+++(81 \%)$ & $+++(86 \%)$ & $+++(85 \%)$ & $+++(85 \%)$ & $-(5 \%)$ & $++(70 \%)$ \\
\hline Systemic profile & $+++(80 \%)$ & $+++(88 \%)$ & $+++(85 \%)$ & $+++(85 \%)$ & $-(4 \%)$ & ++ (70\%) \\
\hline Rheumatic profile & $+++(87 \%)$ & $+++(92 \%)$ & $+++(81 \%)$ & $+++(81 \%)$ & $-(9 \%)$ & $++(64 \%)$ \\
\hline B) Immune system components & Biologics & & & & Non-biologics & \\
\hline & Anakinra & Canakinumab & Sarilumab & Tocilizumab & Methotrexate & Prednisone \\
\hline Innate immune system deregulation & $++(71 \%)$ & $++(71 \%)$ & $+(55 \%)$ & $+(55 \%)$ & $-(10 \%)$ & $++(65 \%)$ \\
\hline $\begin{array}{ll}\text { Adaptive immune system } & \begin{array}{l}\text { T-cell response activation } \\
\text { Defective immune regulation }\end{array}\end{array}$ & $\begin{array}{l}+(45 \%) \\
-(19 \%)\end{array}$ & $\begin{array}{l}-(37 \%) \\
-(37 \%)\end{array}$ & $\begin{array}{l}++(71 \%) \\
+(47 \%)\end{array}$ & $\begin{array}{l}++(71 \%) \\
+(47 \%)\end{array}$ & $\begin{array}{l}-(25 \%) \\
-(15 \%)\end{array}$ & $\begin{array}{l}+(47 \%) \\
+(50 \%)\end{array}$ \\
\hline
\end{tabular}

Figure 1. Kaplan-Meier Estimates of a Combined JADAS27 MDA and CHAQ-DI=0 Response by Age Cohort
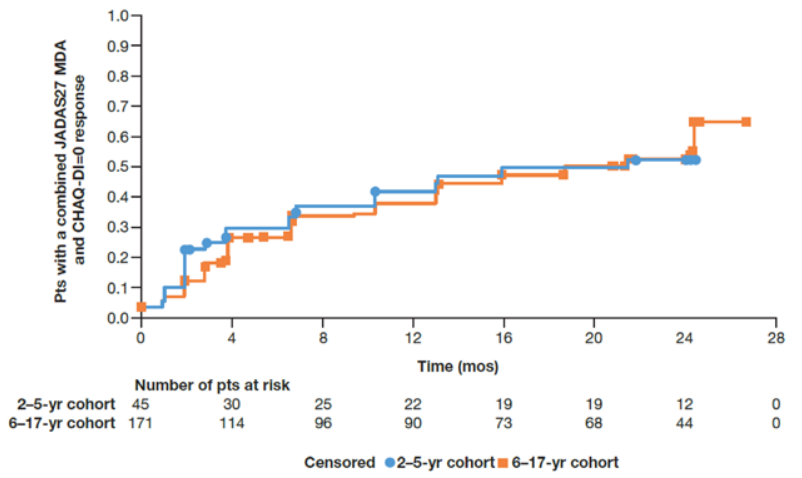

Number of pts with the event of this combined response at baseline: 1

ined JADAS27 MDA and CHAQ-DI=0 response were censored at the date of the last combined $\mathrm{N}$ at Mo 0 is number of treated pts with combined JADAS27 MDA and CHAQ-DI=0 response assessments at Day

Pts who had the event of this combined response at baseline were excluded from the analysis
CHAQ-Dl=Chilchood HAQ-DI; JADAS27=Juvenile Arthritis Disease Activity Score 27; MDA=minimal disease activity; pt=patient

Figure 2. Kaplan-Meier Estimates of a Combined JADAS27 MDA and Pain VAS $<35$ mm Response by Age Cohort

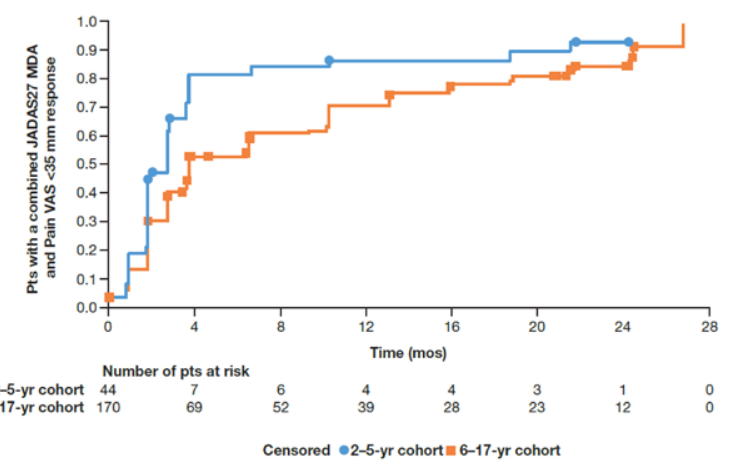

Number of pts with the event of this combined response at baseline: 3

PS without combined JADAS27 MDA and Pain VAS $35 \mathrm{~mm}$ response were censored at the date of the last combined Nat Mo 0 is number of treated pts with combined JADAS27 MDA and Pain VAS $<35 \mathrm{~mm}$ response assessments at Day 1 Pts who had the event of this combined response at baseline were excluded from the analysis

\section{THU0498 PATIENT-REPORTED TREATMENT BURDEN AND ITS IMPACT ON QUALITY OF LIFE IN JUVENILE IDIOPATHIC ARTHRITIS: RESULTS FROM THE PHARMACHILD REGISTRY}

A. Alongi ${ }^{1}$, A. Consolaro ${ }^{2}$, G. Vijatov-Djuric ${ }^{3}$, G. Filocamo ${ }^{4}$, O. Vougiouka ${ }^{5}$, A. N. Olivieri', C. Herrera Mora ${ }^{7}$, W. Emminger ${ }^{8}$, A. Ravelli ${ }^{2}$, N. Ruperto ${ }^{2}$. ${ }^{1}$ Università Degli Studi di Genova, Genoa, Italy; ${ }^{2}$ Istituto Giannina Gaslini,
Genoa, Italy; ${ }^{3}$ University of Novi Sad, Novi Sad, Serbia: ${ }^{4}$ Fondazione IRCCS Ca' Granda-Ospedale Maggiore Policlinico, Milan, Italy; " $P$ a A Kyriakou” Children's Hospital, Athens, Greece; ${ }^{6}$ Second University of Naples F.Fede, Naples, Italy; ${ }^{7}$ Hospital de Niños Roberto Gillbert Elizalde, Guayaquil, Ecuador; ${ }^{8}$ University Children's Hospital, Vienna, Austria

Background: Juvenile Idiopathic Arthritis (JIA) patients experience impaired health and wellbeing due to multiple causes of physical and psychosocial distress, including treatment burden. Despite emerging evidence of its relevance [1], the contribution of treatment adverse events to patient-reported outcomes (PROs) in JIA has been poorly explored.

Objectives: To evaluate and rank the impact of patient-reported adverse events (AEs) on overall wellbeing, health-related quality of life (HRQoL), school problems and self-reported medication adherence using data from Pharmachild, a large international JIA pharmacovigilance registry.

Methods: Registry entries on 5340 prospective visits of 2251 patients enrolled till December 2018 were analyzed; all included patients were treated with at least one DMARDS or Biologic agent at the time of visit. In the Juvenile Arthritis Multidimensional Assessment Report (JAMAR), patients and parents compiled a checklist of treatments, side effects, self-reported adherence, administration difficulties and disease-related school problems occurred in the previous 4 weeks. Evaluated outcomes included patient acceptable symptom state (PASS), VAS-measured patient assessment of overall wellbeing (PGA) and HRQoL, assessed through the physical health $(\mathrm{PhH})$ and psychosocial health $(\mathrm{PsH})$ subscales. The relationships between AEs and PROs were tested through generalized linear models, accounting for disease activity and symptoms levels. Bayesian Networks were used to explore the causal effects of specific AEs on outcomes to disentangle the confounding role of disease status.

Results: AEs were reported in $22.9 \%$ of visits. For similar levels of physician global assessment (MD global), patient-assessed disease activity, pain and function, patients reporting AEs had worse PGA, PsH, and lower probability of reaching PASS (fig. 1, all p-values $<0.001$ ). The impact of AEs on PGA was small but not trivial (effect size $\eta^{2} 0.031$ ) and appears to be mediated by effects on $\mathrm{PsH}$ and school problems $(\mathrm{p}<0.001)$. Non-linear regression modelling revealed a significant moderating effect of $M D$ global levels $<2.5$ on the relationship between AEs and PGA ( $p$ 0.003), indicating that the impact of AEs is higher for lower disease activity states. AEs predicted self-reported medication adherence $(p<0.001)$, even when adjusted for the number of administered treatments. In the Bayesian network model, mood swing and sleep problems emerged as the most influential items affecting $\mathrm{PsH}$, (respectively, total effect 2.62 and 1.25 , both $p<0.001$ ). Fig. 2 shows the total standardized effect of specific AEs on mean PsH levels. Nausea had the highest impact on treatment adherence (total effect $-0.0541, p<0.001$ ), being the only $A E$ directly linked to drug refusal.

Conclusion: AEs have a measurable effect on the wellbeing and psychosocial health of JIA patients, particularly when disease activity is low, and significantly affect school activity and medication adherence. Mood swings and sleep problems show the strongest influence on HRQoL. Addressing AEs appears important to reduce disease impact, improve patients' satisfaction and therapeutic compliance.

References: :

[1] Weitzman, Elissa R., et al. Journal of patient-reported outcomes 2.1 (2018): 1. 


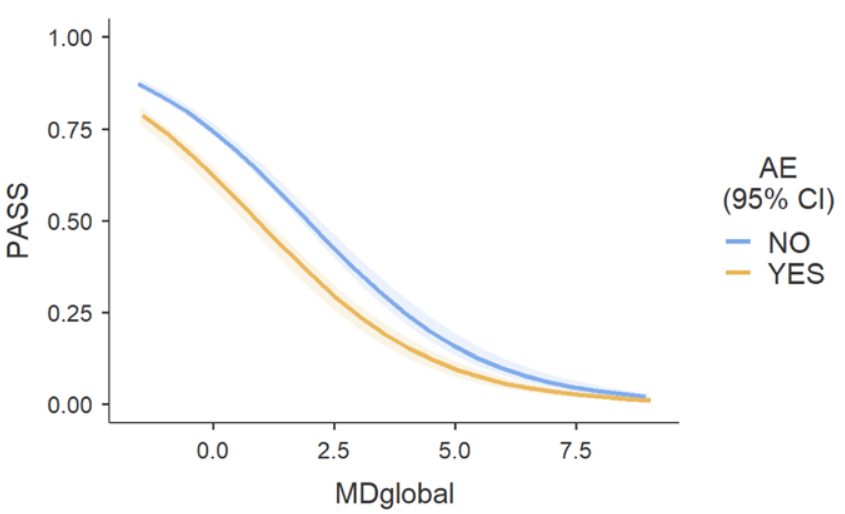

Pstrs

m

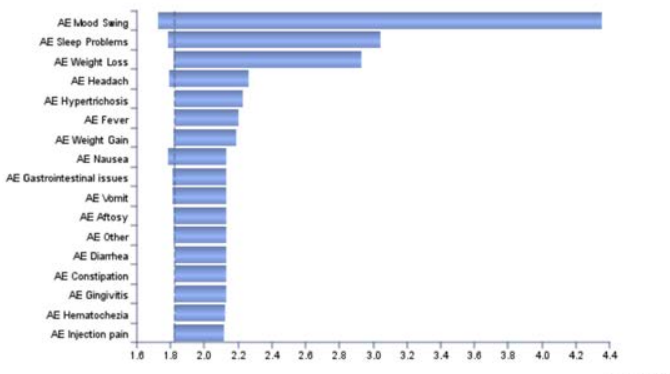

Acknowledgments: for the Paediatric Rheumatology International Trials Organisation (PRINTO)

Disclosure of Interests: : Alessandra Alongi: None declared, Alessandro Consolaro Grant/research support from: Pfizer Inc., AlfaSigma, Speakers bureau: AbbVie, Gordana Vijatov-Djuric: None declared, Giovanni Filocamo: None declared, Olga Vougiouka: None declared, Alma Nunzia Olivieri: None declared, Cristina Herrera Mora: None declared, Wolfgang Emminger: None declared, Angelo Ravelli: None declared, Nicolino Ruperto Grant/research support from: Bristol-Myers Squibb, Eli Lily, F Hoffmann-La Roche, GlaxoSmithKline, Janssen, Novartis, Pfizer, Sobi (paid to institution), Consultant of: Ablynx, AbbVie, AstraZeneca-Medimmune, Biogen, Boehringer Ingelheim, Bristol-Myers Squibb, Eli Lily, EMD Serono, GlaxoSmithKline, Hoffmann-La Roche, Janssen, Merck, Novartis, Pfizer, R-Pharma, Sanofi, Servier, Sinergie, Sobi, Takeda, Speakers bureau: Ablynx, AbbVie, AstraZeneca-Medimmune, Biogen, Boehringer Ingelheim, Bristol-Myers Squibb, Eli Lily, EMD Serono, GlaxoSmithKline, Hoffmann-La Roche, Janssen, Merck, Novartis, Pfizer, R-Pharma, Sanofi, Servier, Sinergie, Sobi, Takeda

DOI: 10.1136/annrheumdis-2020-eular.5816

\section{THU0499 IS THERE A DIFFERENT PRESENTATION OF JUVENILE SYSTEMIC DIFFUSE AND LIMITED SUBSET? DATA FROM THE JUVENILE SCLERODERMA INCEPTION COHORT. WWW.JUVENILE-SCLEORDERMA.COM}

I. Foeldvari ${ }^{1}$, J. Klotsche ${ }^{2}$, O. Kasapcopur ${ }^{3}$, A. Adrovic ${ }^{3}$, K. Torok ${ }^{3}$, M. T. Terreri ${ }^{3}$, A. P. Sakamoto ${ }^{3}$, V. Stanevicha ${ }^{3}$, F. R. Sztajnbok ${ }^{3}$, J. Anton ${ }^{3}$, B. Feldman ${ }^{3}$, E. Alexeeva ${ }^{3}$, M. Katsikas ${ }^{3}$, V. Smith ${ }^{3}$, E. Marrani ${ }^{3}$, M. Kostik ${ }^{3}$, N. VasquezCanizares $^{3}$, S. Appenzeller ${ }^{3}$, M. Janarthanan ${ }^{3}$, M. Moll ${ }^{3}$, D. Nemcova ${ }^{3}$, A. Patwardhan ${ }^{3}$, M. J. Santos ${ }^{3}$, S. Sawhney ${ }^{3}$, D. Schonenberg ${ }^{3}$, C. Battagliotti ${ }^{3}$, L. Berntson ${ }^{3}$, B. Bica ${ }^{3}$, J. Brunner ${ }^{3}$, P. Costa Reis ${ }^{3}$, D. Eleftheriou ${ }^{3}$, L. Harel ${ }^{3}$, G. Horneff ${ }^{3}$, D. Kaiser ${ }^{3}$, D. Lazarevic ${ }^{3}$, K. Minden ${ }^{2}$, S. Nielsen ${ }^{3}$, F. Nuruzzaman ${ }^{3}$, Y. Uziel ${ }^{3}$, N. Helmus ${ }^{1} .{ }^{1}$ Hamburg Centre for Pediatric and Adolescence Rheumatology, Hamburg, Germany; ${ }^{2}$ German Rheumatism Research Center, Berlin, Germany; ${ }^{3}$ jSSc Collaborative Group, Hamburg, Germany

Background: Juvenile systemic scleroderma (jSSc) is an orphan disease with a prevalence of 3 per 1000000 children. There are limited data regarding the clinical presentation of jSSc. The Juvenile Systemic Scleroderma Inception Cohort
(JSSIC) is the largest multinational registry that prospectively collects information about jSSc patients.

Objectives: Evaluation of the jSSc patients at the time of inclusion in the JSSIC. Methods: Patients were included in the JSSIC if they fulfilled the adult ACR EULAR classification criteria for systemic scleroderma, if they presented the first non-Raynaud symptom before 16 years of age and if they were younger than 18 years of age at time of inclusion. Patients' characteristics at time of inclusion were evaluated.

Results: Until $15^{\text {th }}$ of December 2019 hundred fifty patients were included, $83 \%$ of them being Caucasian and $80 \%$ female. The majority had the diffuse subtype (72\%) and $17 \%$ of all jSSc had overlap features. The mean age of first presentation of Raynaud's phenomenon was 9.8 years in the diffuse subtype (djSSc) and 10.7 years in the limited subtype (IjSSc) $(p=.197)$. The mean age at first non-Raynaud's symptoms was 10.0 years in the djSSc and 11.2 years in the ljSSc $(p=0.247)$. Mean disease duration at time of inclusion was 3.4 years in the djSSc and 2.4 years in the ljSSc group.

Significant differences were found between the groups regarding mean modified Rodnan skin score, 18.2 in the djSSc vs 6.2 in the ljSSc $(p=0.02)$; presence of Gottron's papulae (djSSc $30 \%$ vs ljSSc $13 \%, p=0.43$ ); presence of teleangiectasia (djSSc $42 \%$ vs $18 \%$ ljSS, $p=0.01$ ); history of ulceration (djSSc $42 \%$ vs $18 \%$ ljSSc, $p=0.008$ ); 6 Minute walk test below the $10^{\text {th }}$ percentile (djSSc $85 \%$ vs ljSSc $54 \%, p=0.044$ ), total pulmonary involvement (djSSc $49 \%$ vs ljSSc $31 \%$, $p=0.045$ ), cardiac involvement (ljSSc $17 \%$ vs djSSc $3 \%, p=0.002)$. djSSc patients had significantly worse scores for Physician Global Assessment of disease activity compared to ljSSc patients (VAS 0-100) (40 vs 15) $(\mathrm{p}=0.001)$ and for Physician Global Assessment of disease damage (VAS 0-100) (36 vs 17) $(\mathrm{p}=0.001)$.

There were no statistically significant differences in the other presentations. Pulmonary hypertension occurred in approximately $6 \%$ in both groups. No systemic hypertension or renal crisis was reported. ANA positivity was $90 \%$ in both groups Anti-Scl70 was positive in $35 \%$ in djSSc and $36 \%$ in the ljSSc group. Anticentromere positivity occurred in $3 \%$ in the djSSc and $7 \%$ in the ljSSc group.

Conclusion: In this unique large cohort of jSSc patients there were significant differences between djSSc and ljSSc patients at time of inclusion into the cohort regarding skin, vascular, pulmonary and cardiac involvement. According to the physician global scores the djSSc patients had a significantly more severe disease. Interestingly the antibody profile was similar in both scleroderma phenotypes.

Supported by the "Joachim Herz Stiftung"

Disclosure of Interests: : Ivan Foeldvari Consultant of: Novartis, Jens Klotsche: None declared, Ozgur Kasapcopur: None declared, Amra Adrovic: None declared, Kathryn Torok: None declared, Maria T. Terreri: None declared, Ana Paula Sakamoto: None declared, Valda Stanevicha: None declared, Flávio R. Sztajnbok: None declared, Jordi Anton Grant/ research support from: grants from Pfizer, abbvie, Novartis, Sobi. Gebro Roche, Novimmune, Sanofi, Lilly, Amgen, Grant/research support from: Pfizer, abbvie, Novartis, Sobi. Gebro, Roche, Novimmune, Sanofi, Lilly, Amgen, Consultant of: Novartis, Sobi, Pfizer, abbvie, Consultant of: Novartis, Sobi, Pfizer, abbvie, Speakers bureau: abbvie, Pfizer, Roche, Novartis, Sobi, Gebro, Speakers bureau: abbvie, Pfizer, Roche, Novartis, Sobi, Gebro, Brian Feldman Consultant of: DSMB for Pfizer, OPTUM and AB2Bio, Ekaterina Alexeeva Grant/research support from: Roche, Pfizer, Centocor, Novartis, Speakers bureau: Roche, Novartis, Pfizer., Maria Katsikas: None declared, Vanessa Smith Grant/research support from: The affiliated company received grants from Research Foundation - Flanders (FWO), Belgian Fund for Scientific Research in Rheumatic diseases (FWRO), Boehringer Ingelheim Pharma GmbH \& Co and Janssen-Cilag NV, Consultant of: Boehringer-Ingelheim Pharma $\mathrm{GmbH} \& \mathrm{Co}$, Speakers bureau: Actelion Pharmaceuticals Ltd, Boehringer-Ingelheim Pharma GmbH \& Co and UCB Biopharma Sprl, edoardo marrani: None declared, Mikhail Kostik: None declared, Natalia Vasquez-Canizares: None declared, Simone Appenzeller: None declared, Mahesh Janarthanan: None declared, Monika Moll: None declared, Dana Nemcova: None declared, Anjali Patwardhan: None declared, Maria Jose Santos Speakers bureau: Novartis and Pfizer, Sujata Sawhney: None declared, Dieneke Schonenberg: None declared, Cristina Battagliotti: None declared, Lillemor Berntson Consultant of: paid by Abbvie as a consultant, Speakers bureau: paid by Abbvie for giving speaches about JIA, Blanca Bica: None declared, Juergen Brunner Grant/research support from: Pfizer, Novartis, Consultant of: Pfizer, Novartis, Abbvie, Roche, BMS, Speakers bureau: Pfizer, Novartis, Abbvie, Roche, BMS, Patricia Costa Reis: None declared, Despina Eleftheriou: None declared, Liora Harel: None declared, Gerd Horneff Grant/research 